\title{
A spectrocolorimetric study on color modification of heat-treated wood during artificial weathering
}

Xianai Huang ${ }^{\mathrm{a}}$, Duygu Kocaefe ${ }^{* a}$, Yasar Kocaefe ${ }^{\mathrm{a}}$, Yaman Boluk ${ }^{\mathrm{b}}$, Andre Pichette

${ }^{a}$ Université du Québec à Chicoutimi, Canada

555, boul. de l'Université, Chicoutimi, Québec, Canada G7H 2B1

${ }^{b}$ University of Alberta, Canada

3-142 Markin/CNRL Natural Resources Engineering Facility

Edmonton, Alberta, Canada T6G 2W2

\begin{abstract}
Effect of artificial weathering on the wood surface color modifications of three North American species (jack pine, aspen, and birch) heat-treated under different temperatures was studied by spectrocolorimetric colormeter (datacolor, CHECK TM). Data was analysed using the reflectance spectra $(400-700 \mathrm{~nm})$ as well as the CIE-L*a*b* system and $\Delta \mathrm{E}$. Kubelka-Munk (K-M) spectra of samples were recorded as a function of artificial weathering time to obtain the absorption maxima of the chromophore woods formed during artificial weathering. The results were compared with those of the respective untreated (Kiln-dried) species. Chemical components of heat-treated and untreated species before and after artificial weathering of $1512 \mathrm{~h}$ were analyzed to understand the degradation mechanism and color changes during heat treatment and artificial weathering.
\end{abstract}

Keywords: Heat-treated wood; color modifications; artificial weathering; Chemical component degradation; Reflectance spectra; Kubelka-Munk; CIE-L*a*b* parameters

*Corresponding author: Tel.:+1- 418-545 5011-5215; fax: +1-418-545-5012

Email address: dkocaefe@uqac.ca 


\section{Introduction}

Heat-treated wood is a relatively new product treated at high temperatures in the range of 180 and $260^{\circ} \mathrm{C}$, depending on the species used and the desired material properties [1]. Heat treatment changes both chemical and physical properties of wood. Decrease of amorphous polysaccharide content (hemicelluloses), condensation and demethoxylation of lignin, and removal of certain extractives occurring due to heat treatment at high temperatures were reported [2-4]. Consequently, heat-treated wood possesses new physical properties such as reduced hygroscopy, improved dimensional stability, better resistance to degradation by insects and micro-organisms, and most importantly, attractive darker color. Wood color is important for wood applications in terms of aesthetic considerations, and sometimes may determine its value in the market [5]. The new versatile properties and attractive darker color make heat-treated wood popular for outdoor applications.

It is well known that natural untreated wood is susceptible to environmental degradation induced by weathering factors such as solar radiation (ultraviolet (UV), visible, and infrared light), moisture (dew, rain, snow, and humidity), temperature, and oxygen[6]. The degradation of untreated wood due to weathering has been the subject of many research papers, review articles and books in connection with color changes, chemical changes and structural changes. Abundant studies on the color changes of untreated commercial woods during weathering have been carried out [7-9]. The colors of untreated wood vary rapidly when exposed to weathering. First, it becomes more yellow or brown, then becomes darker and finally becomes lighter after a period of weathering with a predominant color of grey. It is well accepted that the wood changes color due to the photo-degradation of lignin and wood extractives [6].The first part of the color change process is because of the formation 
of chromophoric groups as carbonyl and carboxyl groups resulting mainly from degradation of $\alpha$-carbonyl, biphenyl and ring-conjugated double bond structures in lignin and moving the extractives towards to wood surface from inside of wood [10, 11]. The products are leached by the water, leaving a grey surface rich in partially degraded cellulose and poor in lignin content[9]. In general, sunlight irradiation darkens untreated woods. Then, they tend to turn yellow or brown. After, the color of some dark woods tend become lighter [12].

As mentioned above, heat treatment darkens the wood color. Several studies have also shown that weathering results in poor aesthetics for heat-treated wood because of the surface discoloration when exposed to natural and artificial weathering [13-15]. The tristimulus spectrocolorimetry technique has been used to quantify the color modification of heat-treated wood due to weathering. Most of the previous studies on color changes due to weathering of heat-treated wood were limited to study of color data reported by the CIE$\mathrm{L}^{*} \mathrm{a} * \mathrm{~b} *$ system. However, the detailed study of heat-treated wood color changes with reflectance spectra and Kubelka-Munk (K-M) spectra are lacked in the literature; consequently, color changes of wood heat-treated by different heat treatment conditions due to weathering are not completely understood. Although several researches were carried out to study on the heat treatment effects on the Mechanical Properties of jack pine and birch [16-18], there is not any publication available in the literature on discoloration taking place due to the artificial weathering of the heat-treated and untreated specific wood species studied in this study. Furthermore, there is no published study available on the chemical analysis of heat-treated wood main components after weathering. Accordingly, the effect of 
accelerated weathering on color changes of different heat-treated woods is investigated in more detail.

The objectives of this study are to investigate the detailed color variation caused by artificial weathering of three heat-treated regional North American species: softwood jack pine (Pinus banksiana), and hardwood aspen (Populus tremuloides) and birch (Betule papyrifera) due to artificial weathering, and to identify connection between wood discolorations and degradation of wood components. These wood species are traditional and popular in the North American market, especially in Quebec, and have very diverse uses under exterior conditions.

\section{Material and methods}

\subsection{Material}

The following three species, one softwood and two hardwood, which are commonly used for outdoor applications in North America, were studied: jack pine (Pinus banksiana), aspen (Populus tremuloides), and birch (Betule papyrifera). Wood boards of approximately 6500 $\times 200 \times 30 \mathrm{~mm}$ were heat-treated in a prototype furnace of University of Quebec at Chicoutimi (UQAC), Quebec, Canada. Table 1 shows the conditions used during the heat treatment. Then, they were subjected to artificial weathering. Untreated wood boards, kiln dried with the final moisture content of about 12\%, were also exposed to artificial weathering along with specimens heat-treated at high temperatures for comparison purposes. Specimens were arbitrarily selected for a complete statistical randomization. They were stored in a room at $20^{\circ} \mathrm{C}$ and $40 \%$ relative humidity (RH) until they were exposed to the artificial weathering and the characterization tests described below. 
Specimens of $70 \times 65 \mathrm{~mm}$ cross-section on longitudinal surfaces and $20 \mathrm{~mm}$ in length were cut from sapwood of heat-treated and untreated wood, and then planed to have smooth surfaces. The prepared specimens of $70 \times 65 \times 20 \mathrm{~mm}$ were used in artificial weathering tests. The color evaluation was carried out on both longitudinal tangential surface (LT) and longitudinal radial surface (LR) of the wood samples.

\subsection{Artificial weathering tests}

Artificial weathering tests were conducted at the Laval University in collaboration with FPInnovation. The samples are exposed to UV light using a commercial chamber, Atlas Material Testing Technology LLC (USA) Ci65/Ci65A Xenon Weather-Ometer. A controlled irradiance water-cooled xenon arc with a CIRA inner filter and a Soda outer filter was used as the source of radiation to simulate sunlight. Tests were performed according to Cycle 1 of Standard ASTM G155: 102 min Xenon light, 18 min light and water spray (air temperature is not controlled) without dark cycle to simulate rain in natural weathering. The black panel temperature was set up to $63 \pm 3^{\circ} \mathrm{C}$ and the irradiance level was $0.35 \mathrm{~W} / \mathrm{m} 2$ at $340 \mathrm{~nm}$. Heat-treated samples and untreated control samples of each species were exposed to UV light. The irradiation was interrupted after 72, 168, 336, 672, 1008, and $1512 \mathrm{~h}$ of exposure and two samples for each set of experimental conditions were taken out for evaluation of their color. Thus, the values of color measured were the average of two measurements.

\subsection{Color determination}

The surface color of specimens exposed to artificial weathering for different periods was measured using a reflectance spectrophotometer (Datacolor, CHECK TM) with a 
measuring head which has diameter of $10 \mathrm{~mm}$. Equipment calibration was carried out with standards provided by the supplier.

The spectrum is the mean value of nine measurements taken at different positions on wood surface. The Kulbelka-Munk (K-M) equation defines a relationship between the sample spectral reflectance (in \%) and its absorption and scattering characteristics. The K-M spectra were calculated according to the K-M equation given below[19]:

$F\left(r_{\lambda}\right)=\frac{K}{S}=\frac{\left(1-r_{\lambda}\right)^{2}}{2 r_{\lambda}}$

where $\mathrm{K}$ and $\mathrm{S}$ are the absorption and scattering coefficients, respectively. $r_{\lambda}$ can be obtained by equation below:

$r_{\lambda}=\frac{R_{\lambda(\text { sample })}}{R_{\lambda(\text { standard })}}$

where $R_{\lambda(\text { sample) }}$ is the sample reflectance and $R_{\lambda(\text { standard })}$ represents the reflectance of a Whatman cellulose paper (no. 42) with a defined porosity[5].

The color system $\mathrm{L}^{*} \mathrm{a} \mathrm{b}^{*}$ 1976according to the CIELab (Commission Internationale d'Eclairage) standard [20] was used to determinate color modifications. The system is characterized by three parameters, $\mathrm{L}^{*}, \mathrm{a}^{*}$ and $\mathrm{b}^{*}$. A three-dimensional coordinate is assigned in the CIEL*a*b* color space. The $\mathrm{L}^{*}$ represents the lightness intensity ranging from 0 to 100, where 0 represents black and 100 represents white. The $\mathrm{a}^{*}$ value describes the chromatic coordinates on the green/red axis, ranging from -127 (pure green) to +127 (pure red). The $b^{*}$ value represents the position on the blue/yellow axis, ranging from -127 (pure blue) to +127 (pure yellow). The differences in the lightness $\left(\Delta \mathrm{L}^{*}\right)$, in the chromaticity coordinates $\left(\Delta \mathrm{a}^{*}\right.$ and $\left.\Delta \mathrm{b}^{*}\right)$ for the specimens before and after exposure of 
artificial sunlight irradiation were calculated according to the following equations based on a D65 light source by simulating the daylight:

$$
\begin{aligned}
& \Delta \mathrm{L}=\mathrm{L}_{\mathrm{t}}^{*}-\mathrm{L}_{0}^{*} \\
& \Delta \mathrm{a}=\mathrm{a}_{\mathrm{t}}^{*}-\mathrm{a}_{0}^{*} \\
& \Delta \mathrm{b}=\mathrm{b}_{\mathrm{t}}^{*}-\mathrm{b}_{0}^{*}
\end{aligned}
$$

where the subscript " 0 " represents the values before artificial sunlight irradiation, and " $t$ " denotes those after exposure of $t h$.

The total color difference $(\Delta \mathrm{E})$ was calculated as a function of the artificial sunlight exposure time according to the equation given below.

$$
\Delta \mathrm{E}=\left(\Delta \mathrm{L}^{* 2}+\Delta \mathrm{a}^{* 2}+\Delta \mathrm{b}^{* 2}\right)^{\frac{1}{2}}
$$

\subsection{Chemical analysis of wood components}

The untreated (kiln-dried) three wood species, jack pine (sample N.7 shown in Table 1) and aspen (sample N.13 in Table 1) were heat-treated at $210{ }^{\circ} \mathrm{C}$, and birch (sample N.23 shown in Table 1) samples were heat-treated at $215{ }^{\circ} \mathrm{C}$ before weathering. These temperatures were chosen based on the results of heat treatment parameter optimisation studies. In this study, wood samples were collected from two or three different wood boards. Layers of approximately 75-micron in thickness were cut using a microtone from the wood surfaces which were discolored by weathering for $1512 \mathrm{~h}$.

The samples of different experimental sets were ground and classified according to the procedure given in TAPPI Standard T257- os-76 (TAPPI, 1997), and used as obtained for moisture content (TAPPI 211om-93) determination. 
According to TAPPI standard, the extractives of wood samples should be extracted with the solvent mixture of ethanol and benzene. As benzene is known to be extremely hazardous to health, it is replaced with acetone. The extractives are extracted sequentially with acetone and 95\% ethanol using extraction methods given in TAPPI Standard (T204 cm-97). Extractive-free wood samples were obtained according to TAPPI standard sample preparation procedure (TAPPI Standard T 12 os-75). The wood sample powder is extracted sequentially with acetone, 95\% ethanol, and water before determination of acid insoluble lignin content as well as pentosan and holocellulose content. The method of TAPPI Standard T222 om-98 is applied to separate and determine acid insoluble lignin content in extractive-free wood samples. The procedure given in TAPPI Standard T223 cm-84 is used to determine the changes in pentosan content.

The holocellulose is defined as the fraction of carbohydrate (cellulose plus hemicelluloses) in wood which is insoluble in water. The holocellulose was obtained by adding $2.5 \mathrm{~g}$ of extractive-free sample in a 250-ml Erlenmeyer flask to which $80 \mathrm{ml}$ of hot distilled water, $0.5 \mathrm{ml}$ of acetic acid, and $1 \mathrm{~g}$ of $80 \%$ sodium chlorite were added. A 25 -ml Erlenmeyer flask was inverted in the neck of the reaction flask. The mixture was heated in a water bath at $70^{\circ} \mathrm{C}$. After 60 minutes, $0.5 \mathrm{ml}$ of acetic acid and $1 \mathrm{~g}$ of sodium chlorite were added. After each succeeding hour, fresh portions of $0.5 \mathrm{ml}$ acetic acid and $1 \mathrm{~g}$ sodium chlorite were added and mixed. Addition of $0.5 \mathrm{ml}$ acetic acid and $1 \mathrm{~g}$ of sodium chlorite was repeated more than four times until the wood sample was completely separated from lignin. After chloriting of 6 to $8 \mathrm{~h}$, the samples were left without further addition of acetic acid and sodium chlorite in the water bath for overnight. At the end of 24 hours of reaction, the holocellulose was cooled and filtered on a tarred fritted dics glass thimble until the yellow 
color (the color of holocellulose is white) and the odour of chlorine dioxide was removed, washed with acetone, vacuum oven dried at $105^{\circ} \mathrm{C}$ for 24 hours, and then placed in a desiccator for an hour and weighed.

\section{Results and discussion}

\subsection{Chemical analysis of wood main components}

For good understanding of the mechanism of color changes taking place during heat treatment and weathering, quantitative data on the chemical composition of the three wood species is an invaluable tool. The results obtained for the main components of the investigated heat-treated woods before weathering and after weathering of $1512 \mathrm{~h}$ as well as for untreated woods before weathering are summarized in Table 2 .

Wood contains a certain amount of noncellulosic carbohydrates (hemicelluloses). Softwood hemicellulose consists of both pentosans and hexosans; hardwood hemicellulose consists mainly of pentosans. Pentosan content in softwood is about 7 to $10 \%$, and in hardwoods about 19 to 25\% (Tappi 1984). It can be seen from Table 2 that the pentosan contents of all the three species decrease after heat treatment. The decreased contents of pentosan are mostly the same; however, Jack pine shows the much larger variation percentage (42\%) after heat treatment than those of aspen (22\%) and birch (21\%). This indicates that heat treatment decomposes hemicelluloses of both softwood and hardwood with almost the same degree. The results show that the artificial weathering decreased

pentosan contents from $5.26 \%$ to $3.50 \%, 17.88 \%$ to $6.62 \%$ and $13.99 \%$ to $5.48 \%$ for jack pine, birch and aspen, respectively.

Wood contains about 20\% to 30\% lignin. Determination of lignin content of wood provides information for evaluation and application of the processes. Hardness, bleachability and 
other wood properties such as color are also associated with the lignin content (Tappi, 1998). The lignin percent of all three woods studied increase after heat treatment $(28.88 \%$ to $35.9 \%, 19.04 \%$ to $22.71 \%$ respectively). This might be due to smaller influence of heat treatment on lignin content than hemicelluloses. However, the lignin percent of heat-treated woods reduce to maximum $2.5 \%$ after artificial weathering. This suggests that the weathering degrades lignin most significantly compared to other wood components for all the three heat-treated woods.

The holocellulose content slightly decreases after heat treatment, however, significantly increases after artificial weathering for all the three species. The variation of holocellulose and pentosan contents indicates that cellulose is the most stable component of wood during both heat treatment and weathering processes. Lignin is the most sensitive to weathering and pentosan is the most sensitive to heat treatment.

Similar to pentosan content, extractive content slightly reduces due to heat treatment while nearly most of the extractives are degraded by weathering for all three species. The extractive content of jack pine is higher than those of birch and aspen both for untreated and heat-treated woods before and after weathering.

\subsection{Visual observation of surface appearance}

Figs 1(a), 1(b) and 1(c) depict the comparison of color changes and physical changes on tangential surfaces of heat-treated jack pine, aspen and birch during artificial weathering. It can be observed that the color of these three heat-treated woods become lighter and whiter with the increasing weathering time but at different rates. However, it is difficult to analysis color changes of the samples quantitatively from the visual appearance. A detailed analysis 
of color changes with reflectance spectra and CIE-L*a*b* system were carried out and presented below.

\subsection{Color changes during artificial weathering}

3.3.1. Color changes due to artificial weathering reported using reflectance and wavelength data

The wood reflectance spectra of untreated and heat-treated jack pine before weathering and after artificial weathering for $1512 \mathrm{~h}$ as obtained from the spectrocolorimeter are illustrated in Fig. 2 (a). The color of sample darkens due to heat treatment while colors of both untreated and heat-treated samples lighten after weathering of $1512 \mathrm{~h}$. The results show that the reflectance difference of heat-treated jack pine before and after weathering is bigger than that of untreated samples. The similar trend was observed for the other two species.

It is difficult to do spectral analysis for the reflectance spectra as presented in Fig. 2 (a). Fig. 2 (a) and (c) display the Kubelka-Munk (K-M) spectra by applying the Kubelka-Munk (K-M) function to the reflectance spectra of Fig. 2 (a) and plotting the K-M spectrum. These spectra resemble absorption spectra. The K-M spectra refer to the three investigated heat-treated and untreated wood samples before weathering and after weathering for 1512 h. All investigated untreated wood species present an absorption maximum at $420 \mathrm{~nm}$ while heat-treated woods present an absorption maximum near $430 \mathrm{~nm}$. For all three heat-treated species, a shoulder is observed for wavelengths above $600 \mathrm{~nm}$ after $1512 \mathrm{~h}$ of weathering. Visual observation of wood surface appearance shows that the heat-treated woods look darker than untreated woods for both before and after weathering. It can be observed that there is a good correlation between the K-M spectra and the visual observation. The darker heat-treated woods present absorption bands covering a larger range than lighter untreated 
woods in the visible region of the electromagnetic spectrum. As was stated above, hemicellulose is the component which is damaged most during heat treatment, consequently, the lignin content of heat-treated wood increases accordingly. This might explain darker color and higher absorption spectra of heat-treated woods. The results shown in Table 2 suggest that the K-M spectra are also well correlated with the extractive contents for both untreated and heat-treated samples before or after weathering. The species presenting higher absorptions in the visible are those that have the larger extractive content (jack pine> birch >aspen).

Figs.2 (d) and (e) display the K-M spectra of untreated and heat-treated jack pine artificially weathered for different times. The similar trend was observed for the other two species. A well-defined absorption maximum is observed at around $420 \mathrm{~nm}$ for untreated jack pine samples and at $430 \mathrm{~nm}$ for heat-treated samples during the whole duration of artificial weathering. The greatest change of K-M spectra for untreated samples occurs within the first $72 \mathrm{~h}$ of weathering and around the $420 \mathrm{~nm}$ wavelength, which corresponds to a decrease in violet shades. This indicates an increase in yellow and red colors. It is believed that the deepening of coloration is to be due to the formation of chromophores caused by the photo-degradation of untreated wood lignin and the removing of extractives from interior of wood substrate to wood surface due to the high temperature during accelerated weathering test. However, the K-M spectra show a decrease especially around the $420 \mathrm{~nm}$ between the $72 \mathrm{~h}$ and $168 \mathrm{~h}$. This can be seen from Fig. 2 (d) which shows a reversal of the trend seen in the first $72 \mathrm{~h}$ where the K-M spectra increase. At $168 \mathrm{~h}$ the KM spectra declines with the greatest decrease in the $450 \mathrm{~nm}$ range again. This is the beginning of leaching processes by water. 
The K-M spectra for heat-treated jack pine samples are illustrated in Fig. 2 (e). The K-M spectra remain the same after weathering for $72 \mathrm{~h}$ and decline slightly up to $168 \mathrm{~h}$, however decrease significantly at $336 \mathrm{~h}$ and then continue to decrease with lower rates as weathering time increases. The different K-M spectra changes pattern of heat-treated wood samples at the earlier stage of weathering with that of untreated samples might be explained by the different lignin contents and extractive contents of untreated and heat-treated wood. Due to degradation of hemicelluloses during heat treatment process, the lignin concentration of heat-treated wood is higher than that of untreated wood (see Table 2), which results in a resistance of heat-treated wood to photo-degradation. Consequently, the changes of K-M spectra of heat-treated wood samples are less than those of untreated wood when weathered up to 72 h. Furthermore, this can be confirmed by the K-M spectra of samples after weathering for 1512 h shown in Fig. 2 (c), where the absorption intensity of heat-treated samples are higher than those of untreated samples. This means the colors on heat-treated wood surface stay darker than those of untreated samples after photo-degradation and leaching by water during weathering. The slight change of K-M spectra during the earlier times of weathering of heat-treated wood also might be explained by the less extractive content removal from the interior heat-treated wood towards the surface.

As observed from Figs. 2 (d) and (e), the intensity of the absorption bands in the K-M spectra for untreated samples increases rapidly during the initial times of weathering until it reaches a highest value after $72 \mathrm{~h}$. Then it decreases with the increasing weathering time. However, the absorption intensities of heat-treated wood decline as the weathering time increases. In order to compare and quantify the observed color changes during weathering, the time dependence of the absorption intensities were analysed. Fig. 3 shows the results of 
the variation behavior of maximum intensity for untreated and heat-treated samples. It can be observed from the results of untreated woods shown in Fig. 3 (a) that the color change trends at the earlier times (168 h for jack pine and aspen, $72 \mathrm{~h}$ for birch ) of weathering are different than those at later weathering times. At this stage of weathering, the major changes in the light absorption characteristics of the wood surface are presented by the jack pine. This might be due to the higher extractive and lignin contents of jack pine (see Table 2). The studied untreated woods show almost the same changes in the light absorption characteristics after weathering more than $168 \mathrm{~h}$. The variations in K-M spectra of heattreated woods with weathering time are presented in Fig. 3 (b), which are larger than those of untreated wood for the same species and at the same weathering times. It is also observed that the major changes are presented by the birch decreasing for the other species in the order, jack pine and aspen.

Color modification on wood surface can also be analysed with the CIE-L*a*b* system according to the changes of lightness $\mathrm{L}^{*}, \mathrm{a}^{*}$, and $\mathrm{b}^{*}$ co-ordinates that represent the color pairs red/green and yellow/ blue, respectively [20].This is a frequently used color change analysing method and has picked up some of the color changes in other studies including the color changes of heat-treated wood during artificial weathering $[14,15,21]$. Ayadi and his co-workers (2003) mentioned the color changes of heat-treated ash, beech, maritime and poplar during exposure of UV light. Their study reported, using CIE-L*a*b* system, the measurements of $\Delta \mathrm{E}$ at different times up to $835 \mathrm{~h}$. They also mentioned that untreated woods quickly darken, yellowing and reddening coloration, and the color modifications are softened for heat-treated woods. They related the better photostability of heat-treated wood color to the increase of lignin stability by condensation and phenol content during the heat 
treatment. This is shown clearly by focusing on the color changes of the three North American species heat-treated at different conditions during artificial weathering with water spray.

3.3.2. Color changes due to heat treatment (heat temperature effects) reported using CIE$\mathrm{L} * \mathrm{a} * \mathrm{~b} *$ system

The curves of Fig. 4 were generated in order to verify the existence of a relationship between chromatic variation occurring during heat treatment at different temperatures and total color differences $(\Delta E)$ for three species using the CIE-L*a*b* system. Decrease in a* values indicates a tendency of wood surface to become greener while increase points out to a tendency to become redder. The rate of change of $a^{*}$ values represents the rate of wood color change. All three species show a tendency to become reddish during heat treatment. There is a proportional increase in $\mathrm{a}^{*}$ values with increasing heat treatment temperatures for jack pine. $\mathrm{a}^{*}$ values of both birch and aspen reach their maximum at $205{ }^{\circ} \mathrm{C}$ for birch and at $210{ }^{\circ} \mathrm{C}$ for aspen. After, they decrease decline heat treatment temperature is further increased to $215^{\circ} \mathrm{C}$ for birch and $220{ }^{\circ} \mathrm{C}$ for aspen. Decrease of $b^{*}$ values indicates a tendency of wood surface to become bluer while increase of $b^{*}$ values shows a tendency to become yellower. $\mathrm{b} *$ values of aspen and birch decrease with the increasing heat treatment temperature, although it can be observed that color co-ordinates $b^{*}$ increase after the heat treatment at temperatures lower than $200{ }^{\circ} \mathrm{C}$ characterizing a tendency to become yellowish.

As shown by the modifications of $\mathrm{L}^{*}$ values, lightening and darkening of wood surface can be observed. Fig. 4 (c) shows $L^{*}$ plotted as a function of temperature during heat treatment for the three species. $L^{*}$ is the most sensitive and visualized parameter for the wood surface 
quality during heat treatment. $\mathrm{L}^{*}$ values decreased due to heat treatment for the three investigated wood species, which means that the samples lost lightness. The lightness variation can be distinguished into two phenomena. During the heat treatment at lower temperatures (less $200{ }^{\circ} \mathrm{C}$ ), a slow decrease in the lightness indicates that the wood becomes darker. The variation becomes more significant when heat treatment temperature exceeds $200{ }^{\circ} \mathrm{C}$ for all species. Previous study also reported darkening of wood surface due to heat treatment as a function of heat treatment temperatures and type of wood species [22]. Hemicelluloses of heat-treated wood degraded and consequently lignin contents of heat-treated wood increased proportionally. Thus, changes in lightness of wood during heat treatment are mainly due to the hemicellulose degradation, and wood color becomes darker starting from the beginning of heat treatment. The degradation of hemicelluloses intensifies with increasing heat treatment temperature.

Total color differences $(\Delta \mathrm{E})$ of wood surfaces of three species heat treated at different temperatures are shown in Fig. 4 (d). With increasing heat treatment temperature, the total color differences $(\Delta \mathrm{E})$ of heat-treated jack pine and aspen increase almost at the same rate. The $\Delta \mathrm{E}$ of birch increases from $200^{\circ} \mathrm{C}$ to $205^{\circ} \mathrm{C}$ while it changes slightly from $205^{\circ} \mathrm{C}$ to $215^{\circ} \mathrm{C}$. The temperature $205^{\circ} \mathrm{C}$ was chosen as the final heat treatment temperature for birch wood while $210^{\circ} \mathrm{C}$ was chosen for jack pine and aspen wood according to the physical and mechanical properties. After heat treatment, the color changes of aspen wood are found to be the highest among the three species and those of jack pine are the lowest. These results indicate that the color of hardwood (aspen and birch) changed more significantly then the color of softwood (jack pine) during heat treatment process. This is well correlated with holocellulose content (Table 2). Among the species studied, the color of jack pine changes 
the least and it has the lowest content of holocellulose, which is more sensitive to degradation during heat treatment.

3.3.3. Color changes due to artificial weathering reported using CIE-L*a*b* system

Figs.5 (a-d) show the color changes of untreated and heat-treated jack pine wood on artificially weathered tangential surfaces. Fig.5 (a) shows red-green tint (a*values) of heattreated and untreated jack pine wood due to weathering. Then $a^{*}$ values of untreated sample increase to maximum after weathering of $336 \mathrm{~h}$ and decrease to the same value after weathering for $1512 \mathrm{~h}$. On the other hand, a*values of woods heat-treated at $190{ }^{\circ} \mathrm{C}$ and $210{ }^{\circ} \mathrm{C}$ decline at all times of weathering. The change trends of $b^{*}$ values are similar to those of $\mathrm{a}^{*}$ values (see Fig.5 (b)). The initial and finial b*values after weathering of $1512 \mathrm{~h}$ are mostly the same on different jack pine surfaces. That indicates both heat-treated and untreated jack pine wood displays the same levels of yellow after weathering. $L^{*}$ value changes of untreated jack pine are irregular compared to those of heat-treated wood, which decline at the initial step of weathering up to a minimum value at $168 \mathrm{~h}$, and then increase and decrease alternately(see Fig.5 (c)). Lightness of untreated jack pine is higher than those of all heat-treated woods before weathering while the results are opposite after weathering more than 1008 h. As it can be seen from Fig. $5(d)$, the total color differences $(\Delta E)$ of heattreated jack pine change more significantly than that of untreated wood. This is due to the difference in their initial color. The color of both untreated and heat-treated wood change to white and gray at the end of the weathering; however, the original color of heat-treated wood is darker than the original color of untreated wood.

The lightness and total color changes on tangential surfaces of heat-treated and untreated birch wood during artificial weathering are shown in Fig.5 (e) and (f). L* value displays 
different trends for heat-treated and untreated birch wood at earlier times of weathering. $L^{*}$ of untreated birch wood decreases to a minimum value after weathering for $72 \mathrm{~h}$ followed by a slow increase and eventually levels off. That implies that untreated wood becomes darker slightly and then becomes lighter as the weathering time increases (Fig.5 (e)). However, the lightness of birch, heat-treated at three temperatures, increases at earlier times of weathering up to a maximum value and then changes slowly. After weathering of 1512 h, the lightness levels of wood heat-treated at $195^{\circ} \mathrm{C}$ are higher than those of untreated wood while those of wood heat-treated at $205^{\circ} \mathrm{C}$ and $215^{\circ} \mathrm{C}$ are lower. Trends observed for $\Delta \mathrm{E}$ values are different for heat-treated and untreated birch wood surfaces. There does not seem to e effect of temperature (see Fig.5 (f)). For heat-treated birch, $\Delta \mathrm{E}$ increases significantly at the earlier times of weathering and then change slowly. However, the $\Delta \mathrm{E}$ values of untreated wood increase slowly and then change rapidly up to $1512 \mathrm{~h}$ of weathering. The total color differences of heat-treated birch are higher after weathering of $1512 \mathrm{~h}$ compared to that of untreated birch wood regardless of heat treatment temperature.

Brightening and darkening of heat-treated and untreated aspen wood are observed by following the changes in $\mathrm{L}^{*}$ values (shown in Fig. 5 (g)). $\mathrm{L}^{*}$ value displays different trends for heat-treated and untreated aspen wood at earlier times of weathering. $L^{*}$ values of untreated aspen wood decrease to a minimum after weathering for $72 \mathrm{~h}$ followed by a slow increase. That implies that untreated wood becomes darker and then becomes lighter as the weathering time increases. The change trends of lightness for heat-treated aspen are different than that of untreated wood, but there does not seem to be any significant effect of heat treatment temperature $\left(200^{\circ} \mathrm{C}, 210^{\circ} \mathrm{C}\right.$, and $\left.220^{\circ} \mathrm{C}\right)$. The values of lightness of heattreated wood increase at earlier times of weathering up to maximum value and then change 
slowly. After weathering of $1512 \mathrm{~h}$, the lightness value of untreated aspen is higher than those of heat-treated aspen. The total color differences $(\Delta \mathrm{E})$ between aspen surfaces are shown in Fig.5 (h). Similar to jack pine and birch, the trends for the change in $\Delta \mathrm{E}$ values are different for heat-treated and untreated aspen wood surfaces. Those of heat-treated wood surfaces are almost the same at different treatment temperatures. $\Delta \mathrm{E}$ values of heattreated aspen increase significantly at earlier times of weathering, and then change slowly. However, $\Delta \mathrm{E}$ values of untreated aspen increase significantly and then decrease rapidly up to $336 \mathrm{~h}$ of weathering. After, they increase again slowly up to $1512 \mathrm{~h}$ of weathering. An overview of the color changes of the three woods heat-treated and subjected to artificial weathering (Fig. 5) allows the following conclusions to be deduced:

1) It is very apparent from the results of this study that weathering has a significant effect on the color of both heat-treated and untreated wood surfaces. It is also apparent from the color data analysed using CIE-L*a*b* system that artificial weathering affects colors of heat-treated wood quite differently from those of untreated wood for the same species, especially at early weathering times $(72 \mathrm{~h})$. These differences found from the analysis carried out using CIE-L*a*b* system are in agreement with results of reflectance and K-M spectra presented earlier. Color parameters of untreated woods are seem to initially increase and then decrease during weathering implying that more than one chemical or physical process is occurring. Significant color changes occur in the first $72 \mathrm{~h}$ of weathering for all three untreated woods although the extent of the color changes varies from wood to wood. The three untreated woods become redder, yellower, and darker in the earlier times of weathering and then the color changes in an opposite direction during later times of weathering. Extractives have antioxidant properties and can limit lightening of wood color 
[21]. The first degradation stage of weathering is believed to be linked to the formation of chromaphoric products induced by lignin scission and removal of extractives from the interior of wood structure towards the surface. With the ongoing weathering process, chromaphoric products are leached out by water and the extractives are damaged, leaving a whiter surface which is rich in cellulose and hemicelluloses. This is confirmed by the result of chemical analysis of wood components (see Table 2) and the white color of holocellulose. Chemical analysis of wood components after heat treatment at high temperatures shows decrease in holocellulose, pentosan and extractives contents of wood (see Table 2), which indicates a degradation of cellulose, hemicelluloses and extractives for woods investigated during this study. Similar results can be found in previous studies [23, 24]. The improvement of lignin and extractive contents after heat treatment observed in the samples analyzed might explain the improvement in color stability of heat-treated woods during the earlier times of weathering. After the specimens have been subjected to long term artificial weathering with simulated sunlight and water spray, the final colors of heattreated woods and untreated woods became similar.

2) Although the color change trends of heat-treated and untreated jack pine, birch, and aspen due to artificial weathering have some similar features, each wood has a uniquely different color change pattern (see Fig. 5 (d), (f) and (h)). It seems that during weathering processes of heat-treated woods, degradation of lignin matrix and extractive take place. This lightens the color and the color difference increases. After, the leaching process of other polymers (such as cellulose and hemicelluloses) on wood surface occurs, consequently, the color returns to initial state and differences between initial and final color decline. The weathering effects on different woods, heat-treated under similar conditions 
$\left(210^{\circ} \mathrm{C}\right.$ for jack pine and aspen, $205^{\circ} \mathrm{C}$ for birch), occur much more rapidly in some species compared to others. The weathering process in heat-treated jack pine appears to be the most rapid among the three wood species studied, followed by heat-treated aspen and birch (see Fig. 5 (d), (f) and (h)). The extent of the color changes also varies among the species. The effect of water spray on jack pine and aspen is higher than it is on birch during weathering due to the different wood structures. The cell wall width of birch is thicker than that of other two species resulting in stronger binder strength and higher resistance to washing by water during weathering. The total color difference of heat-treated jack pine is less than those of both birch and aspen at all weathering times except at $1008 \mathrm{~h}$. Jack pine is softwood and other two wood species studied are hardwoods with somewhat comparably structured lignin polymer component but with distinctive differences in overall composition, as noted in Table 2. The high lignin content of heat-treated jack pine (softwood) protects wood surface more against the weathering process compared to lignin content of other two species.

3) All the color changes on both heat-treated and untreated wood surfaces brought about by the weathering process are essentially complete approximately at 336-672 $\mathrm{h}$ of weathering.

4) After the specimens have been subjected to $1512 \mathrm{~h}$ of artificial weathering with simulated sunlight and water spray, the colors of all three heat-treated woods are found to be very similar.

5) When $\Delta \mathrm{E}$ versus maximum absorption intensity is plotted for each heat-treated and untreated species, the following linear regression analysis following correlation coefficients are achieved: 0.807 for untreated jack pine, 0.778 for heat-treated jack pine, 0.887 for 
untreated birch, 0.942 for heat-treated birch, 0.986 for untreated aspen, 0.968 for heattreated aspen. These deviations from the ideal linear correlation might be attributed to some lost information when a wood reflectance spectrum is transformed to color values [5, 25].

\subsubsection{Direction effects}

Physical and chemical properties of wood are known to be a function of direction. A study of the color change on tangential surfaces (LT) and radial surfaces (LR) of the three heattreated wood was conducted to show if the color changes during weathering were affected by direction. The color of heat-treated jack pine is almost same on radial and tangential surfaces at all the weathering times (see Fig. 6). However, the color changes more on tangential surfaces of heat-treated birch than on radial surfaces at all weathering times. Likewise, the heat-treated aspen shows the similar trend to birch. A statistical analysis (Ttest) is used for the $\Delta \mathrm{E}$ data companion obtained from this study. The significant difference $(\mathrm{P}<0.05)$ in $\Delta \mathrm{E}$ data between the two different direction surfaces was found to occur at $1008 \mathrm{~h}$ and $1512 \mathrm{~h}$ of weathering for heat-treated birch and more than $336 \mathrm{~h}$ of weathering for heat-treated aspen. This is most likely linked to presence of different structures on different direction surfaces. The presence of radial rays causes that water moves rapidly deeper into the wood structure on tangential surfaces than radial surfaces during weathering

process. Consequently, the leaching by water increases inducing more degradation on tangential surfaces compared to radial ones.

\section{Conclusions}

A general understanding of heat-treated wood color behavior under artificial weathering is acquired using spectrocolorimetry. The K-M spectra of heat-treated woods during artificial weathering identified absorption bands that caused by chemical modifications of the wood 
surface, characterizing weathering processes. There is a major increase in yellow and red with corresponding decreases in the reflectance for all the three species during heat treatment. Heat-treated woods have better color stability during the early times of weathering, while the colors of heat-treated woods and untreated woods are very similar after the specimens have been subjected to long term artificial weathering. It is proposed that the weathering mechanism of heat-treated woods consists of degradation of lignin matrix and extractives, which lightens the wood color and the color difference between before and during this stage of weathering increases. Then, the leaching process of other polymers on wood surface occurs, consequently, the color returns back to initial value and color difference decline. The rapidness and extent of the weather effects on different heattreated woods are different. The direction effects of color changes of heat-treated woods due to weathering are different for different species.

\section{Acknowledgements}

The authors thank Fonds québécois de la recherche sur la nature et les technologies (FQRNT), Développement Économique Canada (DEC), Ministère du Développement Économique, de l'Innovation et de l'Exportation (MDEIE), Conférence Régionale des Élus du Saguenay-Lac-St-Jean (CRÉ), Université du Québec à Chicoutimi (UQAC), Fondation de l'Université du Québec à Chicoutimi (FUQAC), FPInnovation, Alberta Innovates, and industrial partners (PCI Ind., Kisis Technology, and Industries ISA), for their technical and financial contributions. The authors also thank Laboratoire d'analyse et de séparation des essences végétales (LASEVE) at UQAC for valuable assistance and technical support during chemical analysis of main wood components. 


\section{References}

[1] Kocaefe D, Shi JL, Yang DQ, Bouazara M. Mechanical properties, dimensional stability, and mold resistance of heat-treated jack pine and aspen. Forest Products Journal. 2008;58:88-93.

[2] Nuopponen M, Wikberg H, Vuorinen T, Maunu SL, Jämsä S, Viitaniemi P. Heattreated softwood exposed to weathering. Journal of Applied Polymer Science. 2004;91:2128-34.

[3] Sivonen H, Maunu SL, Sundholm F, Jämsä S, Viitaniemi P. Magnetic resonance studies of thermally modified wood. Holzforschung. 2002;56:648-54.

[4] Kotilainen R, Alén R, Arpiainen V. Changes in the chemical composition of Norway spruce (Picea abies) at $160-260^{\circ} \mathrm{C}$ under nitrogen and air atmospheres. Paperi ja Puu/Paper and Timber. 1999;81:384-8.

[5] Pastore TCM, Santos KO, Rubim JC. A spectrocolorimetric study on the effect of ultraviolet irradiation of four tropical hardwoods. Bioresource Technology. 2004;93:37-42.

[6] Feist WC, Rowell RM, Barbour RJ. Outdoor wood weathering and protection. Archaeological Wood: Properties, Chemistry, and Preservation. 1990:263-98.

[7] Hon DNS, Minemura N. Color and discoloration. Wood and Cellulosic Chemistry. 2001:385-442.

[8] Kishino M, Nakano T. Artificial weathering of tropical woods. Part 2: Color change. Holzforschung. 2004;58:558-65.

[9] Feist WC, Hon DNS. Chemistry of weathering and protection. The Chemistry of Solid Wood. 1984:401-51. 
[10] Hon DNS, Feist WC. Hydroperoxidation in photoirradiated wood surfaces. Wood Fiber Sci. 1992;24:448-55.

[11] Lin SY, Kringstad KP. Photosensitive groups in lignin and lignin model compounds. Tappi. 1970;53:658-63.

[12] Feist WC. Finishing wood for exterior use. Finishing Eastern Hardwoods Proceedings 87318. 1983:185-98.

[13] Shi Q, Jiang JH. Color stability of heat-treated okan sapwood during artificial weathering. Guilin2011. p. 13-6.

[14] Deka M, Humar M, Rep G, Kričej B, Šentjurc M, Petrič M. Effects of UV light irradiation on colour stability of thermally modified, copper ethanolamine treated and non-modified wood: EPR and DRIFT spectroscopic studies. Wood Science and Technology. 2008;42:5-20.

[15] Dubey MK, Pang S, Walker J. Color and dimensional stability of oil heat-treated radiata pinewood after accelerated UV weathering. Forest Products Journal. 2010;60:453-9.

[16] Kocaefe D, Poncsak S, Tang J, Bouazara M. Effect of heat treatment on the mechanical properties of North American jack pine: Thermogravimetric study. Journal of Materials Science. 2010;45:681-7.

[17] Poncsák S, Kocaefe D, Bouazara M, Pichette A. Effect of high temperature treatment on the mechanical properties of birch (Betula papyrifera). Wood Science and Technology. 2006;40:647-63. 
[18] Lekounougou S, Kocaefe D, Oumarou N, Kocaefe Y. Effect of Thermal modification on Mechanical Properties of Canadian White Birch (Betula papyrifera). International Wood Products Journal. 2011.

[19] Hembree Jr DM, Smyrl HR. Anomalous dispersion effects in diffuse reflectance infrared Fourier transform spectroscopy: A study of optical geometries. Applied Spectroscopy. 1989;43:267-74.

[20] Hunt RWG. The Reproduction of Color. 1995.

[21] Ayadi N, Lejeune F, Charrier F, Charrier B, Merlin A. Color stability of heat-treated wood during artificial weathering. Holz als Roh - und Werkstoff. 2003;61:221-6.

[22] Bekhta P, Niemz P. Effect of high temperature on the change in color, dimensional stability and mechanical properties of spruce wood. Holzforschung. 2003;57:539-46.

[23] Avat F. Contribution à l'étude des traitements Thermiques du bois jusqu'à $300{ }^{\circ} \mathrm{C}$ : Transformations chimiques et caractérisations physico-chimiques. Contribution a L'étude des Traitements Thermiques du Bois Jusqu'à $300{ }^{\circ} \mathrm{C}$ : Transformations Chimiques et Caracterizationsphysico-Chimiques. 1993.

[24] Kollmann F, Schneider A. Über das Sorptionsverhalten wärmebehandelter Hölzer. Holz Roh- Werkstoff. 1963;21:77-85.

[25] Brunner CC, Shaw GB, Butler DA, Funck JW. Using color in machine vision systems for wood processing. Wood Fiber Sci. 1990;22:413-28. 
Fig. 1 Comparison of heat-treated surfaces of three species at different weathering times: (a) jack pine heat-treated at $210{ }^{\circ} \mathrm{C}$; (b) aspen heat-treated at $210{ }^{\circ} \mathrm{C}$; (c) birch heattreated at $215^{\circ} \mathrm{C}$

Fig. 2 Reflectance spectra and K-M spectra for heat-treated woods during weathering: (a) reflectance spectra of jack pine; (b) K-M spectra for the three heat-treated and untreated woods before weathering; (c) K-M spectra for the three heat-treated and untreated woods after weathering for 1512 h; (d) Evolution of K-M spectra for untreated jack pine as a function of weathering time; (e) Evolution of K-M spectra for heat-treated jack pine as a function of weathering time

Fig. 3 Variation of maximum intensity in K-M different spectra between non-weathered and weathered samples as measured at $420 \mathrm{~nm}$ for untreated woods and at $430 \mathrm{~nm}$ for heat-treated woods during weathering: (a) untreated wood; (b) heat-treated wood

Fig. 4 Color changes on tangential surfaces of wood heat-treated at different temperatures reported using CIE-L*a*b* system: (a) red/green coordinate (a*), (b) yellow/blue coordinate ( $\left.\mathrm{b}^{*}\right)$, (c) lightness coordinate $\left(\mathrm{L}^{*}\right)$, (d) total color difference $(\Delta \mathrm{E})$

Fig. 5 Color changes on tangential surfaces of heat-treated woods during artificial weathering reported using CIE-L*a*b* system: (a) red/green coordinate (a*) of jack pine, (b) yellow/blue coordinate (b*) of jack pine, (c) lightness coordinate ( $\left.\mathrm{L}^{*}\right)$ of jack pine, (d) total color difference ( $\Delta E$ ) of jack pine, (e) $L^{*}$ of birch, (f) $\left.\Delta E\right)$ of birch, (g) L* of aspen, (h) $\Delta \mathrm{E}$ ) of aspen

Fig. 6 Comparison of color difference between tangential surfaces (LT) and radial surfaces (LR) of heat-treated woods during artificial weathering 
Table 1 Conditions of heat treatment

\begin{tabular}{|c|c|c|c|c|c|c|}
\hline $\begin{array}{l}\text { Sample } \\
\text { N. }\end{array}$ & $\begin{array}{l}\text { English } \\
\text { name }\end{array}$ & Surface & $\begin{array}{l}\text { Temp. } \\
\left({ }^{\circ} \mathrm{C}\right)\end{array}$ & $\begin{array}{l}\text { Heating } \\
\text { Rate } \\
\left({ }^{\circ} \mathrm{C} / \mathrm{h}\right)\end{array}$ & $\begin{array}{l}\text { Holding } \\
\text { Time } \\
\text { (h) }\end{array}$ & Humidity \\
\hline 1 & Jack pine & $\mathrm{LT}$ & 0 & 1 & / & I \\
\hline 2 & Jack pine & LR & 0 & / & / & / \\
\hline 3 & Jack pine & $\mathrm{LT}$ & 190 & 15 & 1 & Yes \\
\hline 4 & Jack pine & LR & 190 & 15 & 1 & Yes \\
\hline 5 & Jack pine & $\mathrm{LT}$ & 200 & 15 & 1 & Yes \\
\hline 6 & Jack pine & LR & 200 & 15 & 1 & Yes \\
\hline 7 & Jack pine & $\mathrm{LT}$ & 210 & 15 & 1 & Yes \\
\hline 8 & Jack pine & LR & 210 & 15 & 1 & Yes \\
\hline 9 & Aspen & $\mathrm{LT}$ & 0 & / & / & / \\
\hline 10 & Aspen & LR & 0 & / & / & / \\
\hline 11 & Aspen & $\mathrm{LT}$ & 200 & 15 & 1 & Yes \\
\hline 12 & Aspen & LR & 200 & 15 & 1 & Yes \\
\hline 13 & Aspen & $\mathrm{LT}$ & 210 & 15 & 1 & Yes \\
\hline 14 & Aspen & LR & 210 & 15 & 1 & Yes \\
\hline 15 & Aspen & $\mathrm{LT}$ & 220 & 15 & 1 & Yes \\
\hline 16 & Aspen & LR & 220 & 15 & 1 & Yes \\
\hline 17 & Birch & $\mathrm{LT}$ & 0 & / & / & / \\
\hline 18 & Birch & LR & 0 & / & I & / \\
\hline 19 & Birch & $\mathrm{LT}$ & 195 & 15 & 1 & Yes \\
\hline 20 & Birch & LR & 195 & 15 & 1 & Yes \\
\hline 21 & Birch & LT & 205 & 15 & 1 & Yes \\
\hline 22 & Birch & LR & 205 & 15 & 1 & Yes \\
\hline 23 & Birch & $\mathrm{LT}$ & 215 & 15 & 1 & Yes \\
\hline 24 & Birch & LR & 215 & 15 & 1 & Yes \\
\hline
\end{tabular}


Table 2 Quantitative analysis of the components of studied species

\begin{tabular}{lccccc}
\hline & \multicolumn{2}{c}{ Extractive (\%) } & Lignin & $\begin{array}{c}\text { Pentosan } \\
(\%)\end{array}$ & $\begin{array}{c}\text { Holocellulose } \\
\text { (\%) }\end{array}$ \\
\cline { 2 - 3 } & Acetone & Ethanol & & & \\
\hline $\begin{array}{c}\text { Untreated jack pine } \\
\text { before weathering }\end{array}$ & 5.04 & 1.77 & 28.66 & 9.09 & 60.21 \\
$\begin{array}{c}\text { Heat-treated jack pine } \\
\text { before weathering }\end{array}$ & 4.78 & 0.74 & 35.90 & 5.26 & 59.05 \\
$\begin{array}{c}\text { Heat-treated jack pine } \\
\quad \text { weathered for 1512 h }\end{array}$ & 0.91 & 0.55 & 2.14 & 3.50 & 95.54 \\
$\begin{array}{c}\text { Untreated birch before } \\
\quad \text { weathering }\end{array}$ & 4.42 & 1.72 & 20.27 & 22.77 & 79.05 \\
$\begin{array}{c}\text { Heat-treated birch } \\
\text { before weathering }\end{array}$ & 2.40 & 1.13 & 26.41 & 17.88 & 68.78 \\
$\begin{array}{c}\text { Heat-treated birch } \\
\quad \text { weathered for 1512 h }\end{array}$ & 0.54 & 0.23 & 2.36 & 6.62 & 93.71 \\
$\begin{array}{c}\text { Untreated aspen before } \\
\quad \text { weathering }\end{array}$ & 3.51 & 1.36 & 19.04 & 17.94 & 72.70 \\
$\begin{array}{c}\text { Heat-treated aspen } \\
\text { before weathering }\end{array}$ & 2.04 & 1.27 & 22.71 & 13.99 & 70.79 \\
$\begin{array}{c}\text { Heat-treated aspen } \\
\text { weathered for 1512 h }\end{array}$ & 0.29 & 0.30 & 2.50 & 5.48 & 92.13 \\
\hline
\end{tabular}




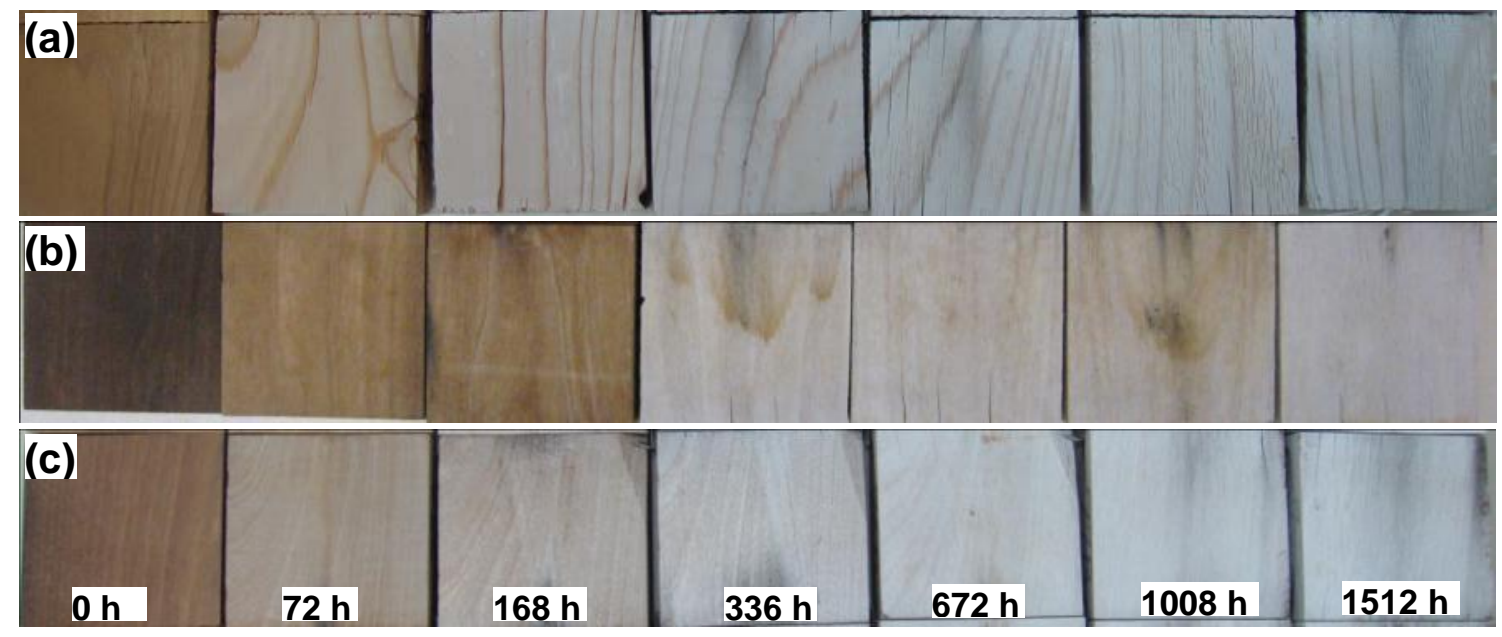

Fig. 1 Comparison of heat-treated surfaces of three species at different weathering times: (a) jack pine heat-treated at $210{ }^{\circ} \mathrm{C}$; (b) aspen heat-treated at $210{ }^{\circ} \mathrm{C}$; (c) birch heat-treated at $215^{\circ} \mathrm{C}$ 
Erreur ! Liaison incorrecte.

Erreur! Liaison incorrecte.Erreur ! Liaison incorrecte.

Erreur ! Qhaison incorrecte.Erreur ! Liaison incorrecte)

Fig. 2 keflectance spectra and K-M spectra for feleat-treated woods during weathering: (a) reflectance spectra of jack pine; (b) K-M spectra for the three heat-treated and untreated woods before weathering; (c) K-M spectra for the three heat-treated and untreated woods after weathering for $1512 \mathrm{~h}$; (d) Evolution of K-M spectra for untreated jack pine as a

function of weathering time; (e) Evolution of K-M spectra for heat-treated jack pine as a function of weathering time 
Erreur ! Liaison incorrecte.Erreur ! Liaison incorrecte.

Fig. 3 Variation of maximum intensity in K-M different spectra between non-weathered and weathered samples as measured at $420 \mathrm{~nm}$ for untreated woods and at $430 \mathrm{~nm}$ for heattreated woods during weathering: (a) untreated wood; (b) heat-treated wood 

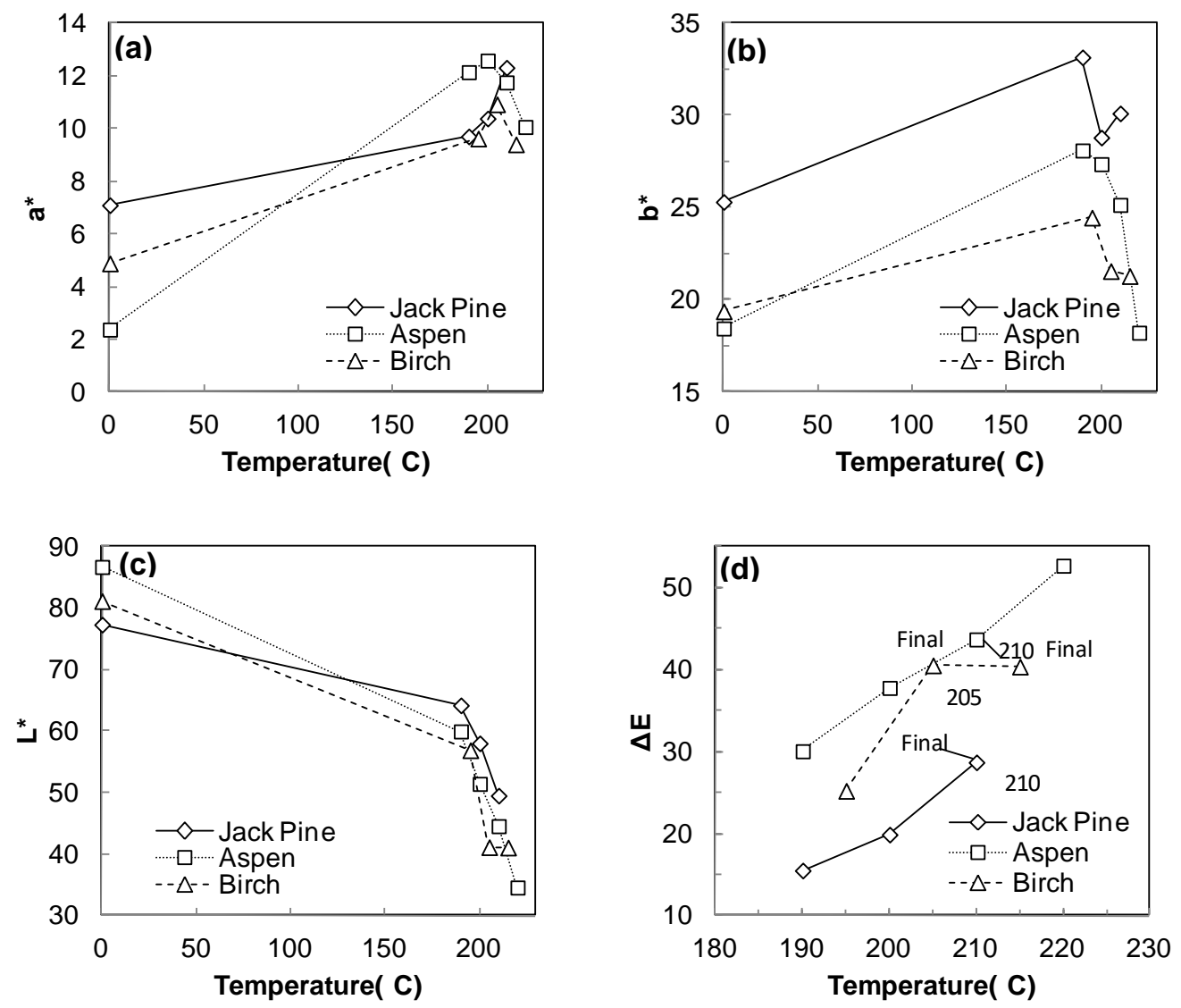

Fig. 4 Color changes on tangential surfaces of wood heat-treated at different temperatures reported using CIE-L*a*b* system: (a) red/green coordinate (a*), (b) yellow/blue coordinate $\left(b^{*}\right),(c)$ lightness coordinate $\left(\mathrm{L}^{*}\right),(\mathrm{d})$ total color difference $(\Delta \mathrm{E})$

\section{Erreur ! Liaison incorrecte.Erreur ! Liaison incorrecte.Erreur ! Liaison incorrecte.Erreur !}

Liaisonln Incorrecte.

(b)

Erreur ! Liaison incorrecte.Erreur ! Liaison incorrecte.

Erreur) (e) Liaison incorrecte.Erreur ! Liaison incorrecte.

Fig. 5 Color Changes on tangential surfaces (LT) of heat-treated woods during artificial weathering reported using CIE-L*a*b* system: (a) red/green coordinate (a*) of jack pine; (b) yellow/blue coordinate (b*) of jack pine; (c) lightness coordinate $\left(\mathrm{L}^{*}\right)$ of jack pine; (d) total color difference $(\Delta \mathrm{E})$ of jack pine; (e) $\mathrm{L}^{*}$ of birch; (f) $\Delta \mathrm{E}$ of birch; (g) L* of aspen; (h) $\Delta \mathrm{E}$ of aspen

(c) 
Erreur ! Liaison incorrecte.Erreur ! Liaison incorrecte.Erreur ! Liaison incorrecte.

Fig. 6 Comparison of color difference between tangential surfaces (LT) and radial surfaces

(LR) of heat-treated woods during artificial weathering 